\title{
Quantifying the contribution of small-scale turbulence to the encounter rates between larval fish and their zooplankton prey: effects of wind and tide ${ }^{*}$
}

\author{
B. R. MacKenzie, W. C. Leggett \\ Department of Biology, McGill University, 1205 ave. Dr. Penfield, Montréal, Québec, Canada H3A 1B1
}

\begin{abstract}
It has recently been suggested that small-scale turbulence can increase the encounter rate between planktonic predators and their prey. In this paper, we quantify the contribution of turbulence to contact rates and estimate the potential for misrepresenting larval contact rates when turbulence is not accommodated in interpretations of the larval food resource. This was achieved through simulations evaluating the nature and magnitude of wind-and tide-induced turbulence on the encounter rate between larval fishes and copepod nauplii. These simulations were based on an empirical model describing turbulent energy levels under varying conditions of wind and depth, and on the SimpsonHunter formulation for depth-averaged turbulence due to tidal motion. The contribution of small-scale turbulence to encounter rates depended strongly on wind and tidal velocities, prey density and distribution, and larval fish swimming speeds. Failure to consider the influence of small-scale turbulence when prey density $\leq 351^{-1}$ can result in up to an 11 -fold underestimation of the frequency of contacts between fish larvae and prey under conditions prevailing at fronts in waters over the northwest European continental shelf during summer, and up to $112 \%$ for larvae at depth $20 \mathrm{~m}$ during wind velocities of $5 \mathrm{~m}$ $\mathrm{s}^{-1}$ These biases increase when prey densities are lower and when prey are heterogeneously distributed. We also show that turbulence may slow the rate of starvation among larval fish because weak, slowswimming individuals are more likely to benefit from turbulence than faster-swimming larvae. We conclude that turbulence, in addition to light and nutrients, may be an important component of the observed increase in plankton production rates and biomass at tidal fronts and at other upwelling systems.
\end{abstract}

\section{INTRODUCTION}

The dissipation of turbulent kinetic energy from large to small size scales is an inherent characteristic of the aquatic environment (e.g. Simpson et al. 1978, Lueck \& Reid 1984, Thorpe 1985). Planktonic organisms respond both actively and passively to fluctuations in turbulent kinetic energy in their habitat (Yamazaki \& Osborn 1988). For example, vertical differences in photoadaptive properties (e.g. maximum photosynthetic rate) of phytoplankton populations are reduced by high turbulence levels (Lewis et al. 1984) and plankton populations are more dispersed in turbulent than in calmer water masses (Lasker 1975, Haury et al. 1990).

\footnotetext{
- Contribution of the programs of the Groupe Interuniver sitaire de Recherches Océanographiques du Québec and the Huntsman Marine Science Centre
}

Small-scale turbulence is suggested to be an important component of plankton trophodynamics (Rothschild \& Osborn 1988), including larval fish (Murphy 1961, Hunter 1972, Sundby \& Fossum 1990). Rothschild \& Osborn (1988) showed analytically that zooplankton feeding rates may be underestimated by failure to consider turbulent motion when assessing the potential frequency of encounters between predators and prey. Sundby \& Fossum (1990) found that the feeding rates of cod larvae increased 2 -fold when winds were $6 \mathrm{~m} \mathrm{~s}^{-1}$, compared to periods when winds were only $2 \mathrm{~m} \mathrm{~s}^{-1}$.

These studies strongly suggest that contact rates, and hence feeding rates of zooplankton and larval fish, may be seriously biased by excluding the contribution of small-scale turbulence to these rates. This is consistent with the recent finding of MacKenzie et al. (1990) that wild populations of larval fish collected during plank- 
ton surveys feed at higher rates than would be predicted from laboratory studies (in which turbulence is absent or reduced) when exposed to equivalent food and temperature conditions. The nature and magnitude of this bias are likely to be related to differences in winds, tides, and water depths, all of which are known to influence the presence and character of small-scale turbulence in aquatic systems (e.g. Lueck \& Reid 1984, Nixon 1988). The precise influence of these factors on plankton encounter rates has not yet been systematically investigated, although they can be evaluated through simulations.

The range of possible contact rates between larvae and prey in nature is vast, given the natural variability in dissipation rates (Osborn 1978, Oakey \& Elliott 1982, Shay \& Gregg 1986), prey densities (Owen 1989, MacKenzie et al. 1990) and swimming speeds of larvae (Miller et al. 1988) and prey (Checkley 1982). Individual larvae may be exposed to only a small portion of this variability because adult spawning and larval swimming behaviours may be adapted to place/maintain larvae in geographic areas (Kiørboe \& Johansen 1986. Sinclair 1988) and/or at depths (Munk et al. 1989) where feeding success is likely to be high. Such locations might include sites of prey aggregations (e.g. thermoclines and fronts; LeFévre 1986) or places where historic wind and tidal conditions increase turbulence, and hence the encounter rates between larvae and their prey.

In this paper we explore, through simulation, some of the meteorological and oceanographic circumstances under which small-scale turbulence created by wind and tide energy might significantly increase contact rates between larval fish and their prey. We also estimate the potential bias produced by failing to recognize the contribution of turbulent motion to the feeding ecology of larval fish in nature. Such knowledge is useful both as a first order guide to correcting larval fish and zooplankton feeding rates in the sea, and as a guide to improving the designs of laboratory experiments in which predator/prey dynamics are explored (Mackenzie et al. 1990).

\section{METHODS}

Estimating the dissipation rate of wind-generated turbulent kinetic energy. Oakey \& Elliott (1982) identified an empirical relationship between wind speed and the depth-averaged rate of dissipation of turbulent kinetic energy, $\varepsilon$, in the mixed layer ( 0 to $\mathrm{ca} 20 \mathrm{~m}$ ) at a site on the Scotian Shelf, Canada. Sundby \& Fossum (1990) used this model to estimate the influence of small-scale turbulence on the encounter rate between cod larvae and their prey near Lofoten, northern Nor- way. However, wind-induced turbulence in the upper layer is known to decrease with depth (Dillon et al. 1981, Oakey 1985, Yamazaki \& Kamykowski 1991). Many species of fish larvae (Heath et al. 1988. Frank \& Carscadden 1989) and zooplankton (McLaren 1963, Williams et al. 1987) have complex vertical distributions. Larval fish and their prey will, therefore, be exposed to variations in turbulence caused by fluctuations of both wind speed and their distance from the water surface. It is, therefore, necessary to estimate small-scale turbulence at different depths within the water column. To assess this question, we used published reports of $\varepsilon$ to develop a multiple regression model incorporating wind speed, water depth and habitat (open ocean, coastal zone) as inputs.

Density gradients within the water column (stratification) may also be important in influencing the rate of dissipation of turbulent kinetic energy (Rothschild \& Osborn 1990, Yamazaki 1990). However these data were reported too infrequently to be included in our analyses. We attempted to minimize the influence of stratification on our estimates of small-scale turbulence by using dissipation rates measured exclusively within the wind-mixed layer where density gradients are small relative to those within the pycnocline.

The model we developed is given by

$$
\begin{gathered}
\log \varepsilon=-5.104 Z^{0079}+0.748 \log \left(W^{3}\right)+0.945 \mathrm{ENV} \\
\mathrm{R}^{2}=0.60
\end{gathered}
$$

where $\varepsilon=$ dissipation rate of turbulent kinetic energy $\left(\mathrm{W} \mathrm{m}^{-3}\right) ; Z=$ water depth $(\mathrm{m}) ; W=$ wind speed $\left(\mathrm{m} \mathrm{s}^{-1}\right) ;$ and $\mathrm{ENV}=$ environment $(\mathrm{ENV}=0$ if turbulence was measured at a site beyond a continental shelf, ENV $=1$ if turbulence was measured on a continental shelf or in a lake)

This model is based on 1138 measurements of the dissipation rate of turbulent kinetic energy at 12 different aquatic sites, of which 11 were marine ( $\mathrm{n}=1132$ ) and 1 was freshwater $(n=6)$. Additional details regarding Eq. (1), and the data used in its derivation, will be reported elsewhere (MacKenzie \& Leggett unpubl.).

We used turbulence values derived from Eq. (1) to calculate the turbulent velocity contribution to the swimming velocity of a predator relative to its prey (Rothschild \& Osborn 1988). In this formulation, when the separation distance, $x(m)$, between predator and prey exceeds the Kolmogorov length scale, $\eta=2 \pi$ $\left(v^{3} / \varepsilon\right)^{0.25}\left(v=\right.$ kinematic viscosity $\left.\approx 10^{-6} \mathrm{~m}^{2} \mathrm{~s}^{-1}\right)$, the turbulent velocity, $w$, is given by

$$
w^{2}=3.615(\varepsilon r)^{2 / 3}
$$

which is Eq. (4) in Rothschild \& Osborn (1988). We assume that the separation distance $r$ is approximated by $N^{-0.333}$, where $N=$ the number of prey per $\mathrm{m}^{3}\left(1 \mathrm{~m}^{3}\right.$ $=10^{3} \mathrm{l}=10^{6} \mathrm{~cm}^{3}$ ). 
The velocity of a larval fish relative to its prey, denoted as $A\left(\mathrm{~cm} \mathrm{~s}^{-1}\right)$, can then be calculated from:

$$
A=\left(s^{2}+3 t^{2}+4 w^{2} / 3\left(t^{2}+w^{2}\right)^{1 / 2}\right.
$$

where $s=$ swimming velocity of the prey $\left(\mathrm{cm} \mathrm{s}^{-1}\right)_{i} t=$ swimming velocity of the larva $\left(\mathrm{cm} \mathrm{s}^{-1}\right)$, and $w=$ turbulent velocity $\left(\mathrm{cm} \mathrm{s}^{-1}\right)$.

Prey contact rate, $C$, is then calculated as

$$
C=A D
$$

where $D=\pi R^{2} N$, and $R(\mathrm{~cm})$ is the encounter radius of the predator (Rothschild \& Osborn 1988).

In employing this derivation of contact rate, we assume, as did Sundby \& Fossum (1990), that the encounter radius, $R$ (also known as the reactive distance, RD; Wanzenböck \& Schiemer 1989), of larval fish is constant in all directions. This may not be strictly true (Rosenthal \& Hempel 1970, Blaxter \& Staines 1971 , Wanzenböck \& Schiemer 1989) but for the present purposes is a reasonable approximation.

In addition, encounter radii for a given predator, even when assumed constant in all directions, vary with factors such as light intensity, size and swimming velocity of the predator, and prey size and conspicuousness (Gerritsen \& Strickler 1977, Lazzaro 1987, Miller et al. 1988, Wanzenböck \& Schiemer 1989). We have excluded exact values of $\pi R^{2}$ from our calculations of contact rate (Eq. 4) to isolate the effects of turbulent velocity, $w^{2}$, and relative velocity, $A$, on larval contact rates. In our simulations, therefore, $D$ is taken to be proportional to prey density $N$. Consequently, contact rate, $C$, is expressed in units of prey $\mathrm{cm}^{-2} \mathrm{~s}^{-1}$. Where the prey encounter radius, $R$, is known, these rates can be converted to prey $s^{-1}$ by multiplying $C$ by the appropriate value of $\pi R^{2}$.

Wind effects on contact rates. We used the empirical turbulence model (Eq. 1) to estimate the contact rates between larvae and prey at several combinations of wind speed and water depth, and at 2 larval swimming velocities. The wind speeds evaluated (0 to $15 \mathrm{~m} \mathrm{~s}^{-1}$ ) spanned the range that occurs over many larval nursery areas (e.g. Bowers \& Simpson 1987, Frank \& Carscadden 1989). The depth range evaluated (0 to $60 \mathrm{~m}$ ) encompasses the vertical range in distribution of many species of marine fish larvae (e.g. Buckley \& Lough 1987, Heath et al. 1988, Frank \& Carscadden 1989, Munk et al. 1989). All simulations assumed larvae were located in a continental shelf habitat (ENV $=1$; Eq. 1).

Larval swimming speeds evaluated were 0.2 and 0.5 $\mathrm{cm} \mathrm{s}^{-1}$. The slower speed is close to the average cruising speed of first-feeding cod larvae (standard length = $4.5 \mathrm{~mm}$; Sundby \& Fossum 1990). Given the relationship between larval size and swimming speed across species, as reported by Miller et al. (1988), the $0.5 \mathrm{~cm}$ $\mathrm{s}^{-1}$ speed approximates that for larvae of total length
$5.7 \mathrm{~mm}$. The 2 swimming speeds were used to evaluate the influence of identical turbulence levels on larvae having different swimming abilities (commonly associated with size; Miller et al. 1988).

The prey modelled were copepod nauplii which constitute the dominant prey of larvae of many commercially exploited marine fish species (Theragra chalcogramma, Dagg et al. 1984; Gadus morhua, Ellertsen et al. 1984; Scomber scombrus, Peterson \& Ausubel 1984. Buckley \& Lough 1987; Clupea harengus, Heath et al. 1989; Melanogrammus aeglefinus, Buckley \& Lough 1987). We assumed that these prey swam at a velocity of $0.02 \mathrm{~cm} \mathrm{~s}^{-1}$ for the simulations involving larval swimming speeds of $0.2 \mathrm{~cm} \mathrm{~s}^{-1}$. This prey velocity is considered to approximate that for Calanus finmarchicus nauplii (Sundby \& Fossum 1990).

We assume that the difference in swimming speeds in the larvae in our simulations is due principally to differences in their sizes and thus, that the faster swimming larvae $\left(0.5 \mathrm{~cm} \mathrm{~s}^{-1}\right)$ prefer larger prey (Hunter 1981). We increased the prey swimming speed in these simulations to $0.05 \mathrm{~cm} \mathrm{~s}^{-1}$. This 10 -fold difference in swimming speeds between prey and fish larvae is consistent with Gerritsen \& Strickler's (1977) observation that vertebrate predators swim much faster than their prey.

We used 2 prey densities (5 and 35 nauplii $1^{-1}$ ) to compare how different levels of turbulence affect contact rates when food supplies differ. These prey densities approximate those found in many larval nursery areas (e.g. Cape Hatteras, North Carolina, USA: Checkley et al. 1988; Lofoten, Norway: Ellertsen et al. 1984; Bering Sea: Dagg et al. 1984\}, but are lower than the median density found in 46 marine environments if one assumes that one copepod nauplius weighs ca 0.2 to $0.5 \mu \mathrm{g}$ dry (MacKenzie et al. 1990).

The spatial distribution of zooplankton, an important characteristic of larval food resources (Owen 1989), is also likely to influence the encounter rate between larvae and their prey. The number, size, and intensity of prey patches is influenced by biotic (e.g. zooplankton migratory behaviours, growth and mortality rates; McLaren 1963, Williams et al. 1987, Owen 1989) and abiotic (wind conditions, water column turbulence; Owen 1989, Haury et al. 1990) factors. However, conventional plankton sampling methods are unreliable in identifying and quantifying the scale and density of these patches (Owen 1989). We, therefore, used our models to quantify (1) the bias in estimates of contact rates that may result when integrative sampling methods are employed and the contribution of turbulence to contact rates is ignored, and (2) how larval contact rates can change with storm-related redistribution of prey (e.g. Lasker 1975).

We compared turbulence-enhanced contact rates 
between slow-swimming larvae and prey under 2 scenarios: (1) prey were patchily distributed on a vertical spatial scale of 5 to $10 \mathrm{~m}$; and (2) prey were distributed homogeneously throughout the $60 \mathrm{~m}$ water column. The first scenario is analogous to a prey distribution which might occur prior to a wind mixing event (Lasker 1975, Frank \& Carscadden 1989) or in areas of weak tidal currents (Bowers \& Simpson 1987). This situation, therefore, considers prey patchiness within a mixed layer (e.g. Peterson \& Ausubel 1984, Checkley et al. 1988, Fortier \& Harris 1989), but not patchiness associated with pycnoclines where Eq. (1) may give unreliable estimates of turbulence.

The scenario involving homogeneously distributed prey corresponds to conditions which might prevail after passage of a storm (Lasker 1975, Owen 1989), or in tidally mixed water columns (Bowers \& Simpson 1987. Heath et al. 1989). The range of wind speeds used in these simulations was restricted to between 0 and $10 \mathrm{~m} \mathrm{~s}^{-1}$ because it is unlikely that prey would remain heterogeneously distributed at higher wind speeds (Owen 1989).

In the pre- and post-storm scenarios, the depth-averaged prey density for the entire water column $(0$ to $60 \mathrm{~m}$ ) was 20 nauplii $\mathrm{l}^{-1}$.

Tidally induced turbulence. To estimate the rate of dissipation of tidally generated turbulent kinetic energy, we derive the viscous dissipation of energy from the large-scale dynamics (p. 19-20 and 68 of Tennekes \& Lumley 1972) of tidal flow. In this formulation, the rate of energy supply from large-scale eddies to small-scale eddies is proportional to $u^{\prime 3} / \ell$, where $\ell$ is the largest eddy size associated with the flow or the width of the flow (Tennekes \& Lumley 1972, Veth 1990).

Bowers \& Simpson (1987) have shown that the potential for tidal flow to completely mix a water column is expressed by a tidal stirring parameter, $u^{3} / h$, where $u$ is the $\mathrm{M}_{2}$ depth-averaged tidal velocity and $h$ is the water column height. Most of the dissipated tidal energy represented by $u^{3} / h$ is lost as heat (Bowers \& Simpson 1987 ), but a percentage of $u^{3} / h$ is available for creating turbulent motion and vertical mixing within the water column (Bowers \& Simpson 1987). If this percentage is denoted as $\xi$, then the absolute amount of dissipated turbulent kinetic energy which results in vertical mixing, $\varepsilon$, can be estimated as

$$
\varepsilon=\zeta u^{3} / h
$$

In Eq. (5), we assume that $u^{3}=\zeta u^{3}$ and that the largest eddy size, $\ell$, is proportional to the water column height, h (Tennekes \& Lumley 1972, Veth 1990).

We used Eq. (5) and values for $u$ and $h$ compiled by Bowers \& Simpson (Table 1; 1987) to estimate the depth-averaged turbulent kinetic energy dissipation rate at tidally energetic sites on the northwest Euro- pean continental shelf during the summer In this region, tidal fronts, which delimit the transition zone between mixed and stratified water columns, are delimited by contours of $u^{3} / h=0.004 \mathrm{~m}^{2} \mathrm{~s}^{-3}$ (Bowers \& Simpson 1987). Depth-averaged turbulent kinetic energy dissipation rates $(\varepsilon)$ in frontal areas can, therefore, be estimated (Eq. 5) as

$$
\begin{aligned}
\varepsilon & =\zeta\left(u^{3} / h\right) \\
& =0.006\left(0.004 \mathrm{~m}^{2} \mathrm{~s}^{-3}\right) \\
& =2.4 \times 10^{-5} \mathrm{~m}^{2} \mathrm{~s}^{-3} \\
& =2.4 \times 10^{-2} \mathrm{~W} \mathrm{~m}^{-3}
\end{aligned}
$$

(Bowers \& Simpson 1987)

where $\zeta=0.006$, the fraction of the dissipated tidal energy which is used for vertical mixing (Bowers \& Simpson 1987). Values of $\varepsilon$ exceeding $2.4 \times 10^{-2} \mathrm{~W} \mathrm{~m}^{-3}$ (i.e. values of $u^{3} / h>0.004 \mathrm{~m}^{2} \mathrm{~s}^{-3}$ ) are typical of tidally mixed areas (Fig. 1 of Rothschild \& Osborn 1988, Bowers \& Simpson 1987, Otto et al. 1990, Veth 1990).

Dissipation rates of turbulent kinetic energy obtained from Eq. (5) were then used as inputs in Eq. (2) to enable calculation of $W^{2}$, and $A$, and, therefore, approximations of the importance of the tidal contribution to contact rates. It is important to note that the tidal velocity term, $u$, in the stirring parameter is a depthaveraged value and that tidally generated turbulence is concentrated near the sea-bottom (Loder \& Greenberg 1986). The depth-averaged contact rates which we derive will, therefore, overestimate contact rates for larvae that feed near the surface. The amount of overestimation will be small for frontal and tidally mixed areas because the source of turbulent energy is, by definition, relatively close to the water surface and because the maximum eddy size from the tidal flow is order $h$. The magnitude of the overestimation will, however, be large for stratified regions where the source of tidal energy is farther from the surface and because the largest eddy size from the tidal flow is $<$ order $h$. For these reasons, we do not quantify the influence of tidal energy on plankton encounter rates in stratified areas. In any case, we anticipate a priori that the contribution of tidal energy to plankton contact rates in the surface layer of a stratified water column will be small relative to the contribution of wind, and in comparison to tidally energetic areas.

In our analysis of the influence of tidally generated turbulence, we conducted 2 types of simulations using only slow-swimming larvae and slow-swimming prey. First we assessed how spatial variations in tidally generated turbulence might affect contact rates when prey densities were uniform across 3 types of hydrographic environments (no tidal energy, frontal, well-mixed). This simulation was conducted with 4 prey densities: 5 , 20,35 and 70 nauplii $l^{-1}$. Next we assessed how the combined spatial variance in both turbulence and prey 
For some combinations of prey density and depth, contact rates estimated from vertically integrated samples and without reference to the contribution of turbulent kinetic energy (Fig. 3B, curve II) may actually overestimate contact rates (e.g. $60 \mathrm{~m}$; Fig. 3B, curves II and III).

\section{Storm effects}

The increases in small-scale turbulence and changes in prey distribution associated with storms can have either detrimental or beneficial effects on larval contact rates. For example, if larvae are located at $20 \mathrm{~m}$ where prey density is $50 \mathrm{l}^{-1}$ and if the wind speed is $5 \mathrm{~m} \mathrm{~s}^{-1}$, their contact rates will decrease by $32 \%$ during a storm having $10 \mathrm{~m} \mathrm{~s}^{-1}$ winds (Fig. 4), assuming that the storm homogenizes prey densities throughout the water column. The decrease in contact rates would have been even greater if not for the increase in turbulence generated by a doubling of wind speed. Moreover if this same larva was mixed downwards or actively swam to deeper water (e.g. $40 \mathrm{~m}$ ), its post-storm contact rate would be reduced by $46 \%$ (Fig. 4). These interactions probably contribute to the negative influence of strong wind events on in situ survival of larval anchovy (Peterman \& Bradford 1987).

It is important to note, however, that under other circumstances fish larvae may also benefit from storm events. In our simulation, larvae located at $40 \mathrm{~m}$ before

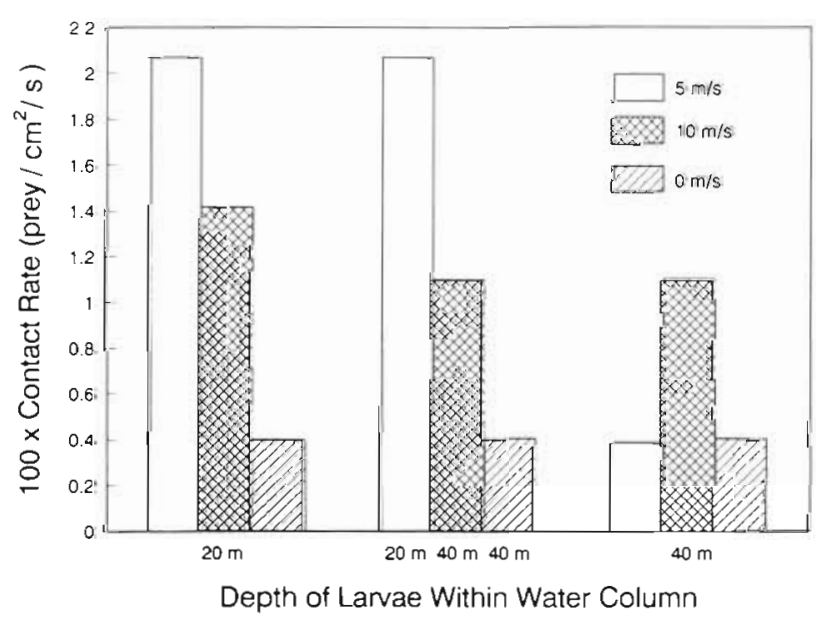

Fig. 4. Simulated influence of a storm on contact rates between larval fish and their zooplankton prey. Pre-storm prey densities vary with depth as follows: $5 \mathrm{I}^{-1}$ for depths $=2$ and $60 \mathrm{~m} ; 10 \mathrm{l}^{-1}$ for depth $=5,35,40$ and $50 \mathrm{~m} ; 15 \mathrm{l}^{-1}$ for depth $=30 \mathrm{~m} ; 25 \mathrm{l}^{-1}$ for depth $=10 \mathrm{~m} ; 40 \mathrm{l}^{-1}$ for depths $=15$ and $25 \mathrm{~m}$; and $50 \mathrm{I}^{-1}$ for depth $=20 \mathrm{~m}$. The depth-averaged prey density before the storm is $201^{-1}$. Prey densities during and after the storm are homogeneous with depth at $20 \mathrm{l}^{-1}$. Wind speeds before, during and after the storm are 5, 10 and $0 \mathrm{~m} \mathrm{~s}^{-1}$, respectively. Larval swimming speed is $0.20 \mathrm{~cm} \mathrm{~s}^{-1}$ and prey swimming speed is $0.02 \mathrm{~cm} \mathrm{~s}^{-1}$ the storm passed would experience a $187 \%$ increase in encounter rates during the storm. This occurs because prey densities increased in deep water due to redistribution of prey from shallower waters, and because of the storm-related increase in small-scale turbulence. At these depths contact rates can be expected to diminish slowly as winds slacken and turbulence dissipates during the post-storm period. They will, however, continue to equal or exceed pre-storm levels because prey densities are now double the pre-storm levels.

\section{Tidally induced turbulence}

In simulations in which prey densities were uniform across 3 hydrographic regimes representing different levels of tidally generated turbulence, contact rates increased with increased tidal mixing (Fig. 5). For example, at prey densities of $351^{-1}$, an 11 -fold increase in contact rate might be expected as a consequence of the tidal energy input that occurs in a frontal region $\left(u^{3} / h=0.004 \mathrm{~m}^{2} \mathrm{~s}^{-3}\right.$; Bowers \& Simpson 1987).

When prey densities differ across hydrographic regions, the contribution of tidal energy to plankton contact rates can be even greater For example, prey densities in a water column having no turbulence would have to be $14 \times$ higher $\left(701^{-1}\right.$; Fig. 5) to produce contact rates equivalent to those at a frontal zone where prey density is only $51^{-1}$.

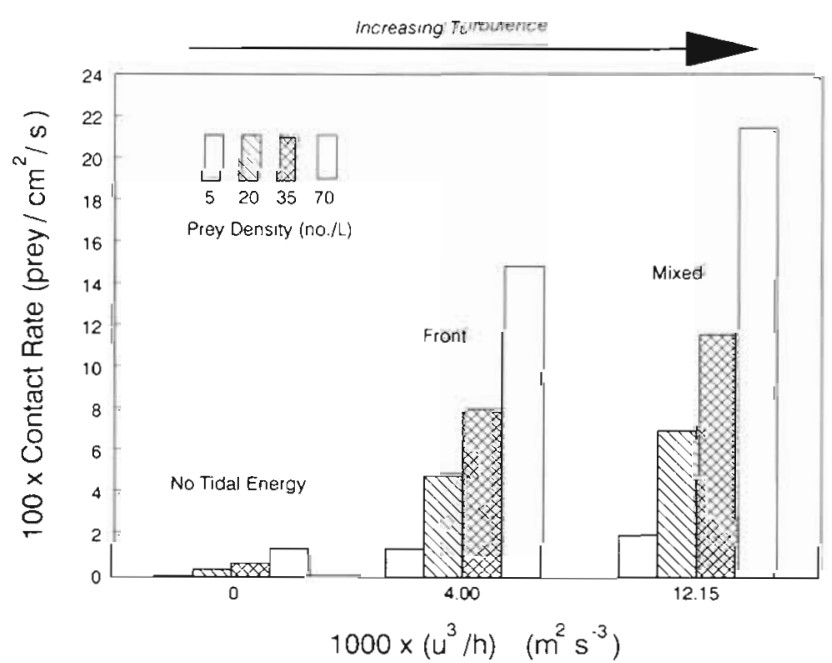

Fig. 5. Contribution of tidal energy to contact rates between fish larvae and their zooplankton prey at 4 prey densities. Larval swimming speed $=0.20 \mathrm{~cm} \mathrm{~s}^{-1}$ and prey swimming speed $=0.02 \mathrm{~cm} \mathrm{~s}^{-1}$. The horizontal axis displays the Simpson-Hunter (1974) stratification index, from which $\varepsilon$, the dissipation rate of turbulent kinetic energy, can be estimated (see text, Eq. 5). A value of $1000 \times\left(u^{3} / h\right)=4 \mathrm{~m}^{2} \mathrm{~s}^{-3}$ occurs at tidally generated fronts (Bowers \& Simpson 1987, p. 37). Values of $1000 \times\left(u^{3} / h\right)>4 \mathrm{~m}^{2} \mathrm{~s}^{-3}$ are characteristic of tidally mixed water columns. In these simulations, tidal velocities, $u$, were $0,0.620$ and $0.900 \mathrm{~m} \mathrm{~s}^{-1}$, and $h=60 \mathrm{~m}$ 


\section{DISCUSSION}

Estimating the realized food abundance and assessing its influence on feeding and growth rates of natural populations of larval fish is a major challenge in fisheries oceanography. Most conventional sampling programs cannot estimate the quantity of prey available to larval fish at the appropriate spatial scales (Owen 1989). Further, they fail to identify larval behavioural responses to prey patchiness at these scales (centimetresmetres; Hunter \& Thomas 1974, Munk \& Kiørboe 1985), and link mortality rates to coincident measures of food density (e.g. Taggart \& Leggett 1987). In addition, predators of larval fish have the potential to remove larvae selectively from the water column (Bailey \& Houde 1989). Larval populations which are captured in plankton collections may, therefore, be growing at rates different from the average for their cohort and independently of the potentially biased estimates of the larval food resource (MacKenzie et al. 1990).

The simulations which we developed from our estimates of wind-and tidal-induced turbulent energy demonstrate the important effect of small-scale turbulence on contact rates between fish larvae and their prey. Failure to recognize the influence of turbulence has undoubtedly biased earlier estimates of the contact rates between larvae and prey (Rothschild \& Osborn 1988), and hence of in situ ingestion rates (MacKenzie et al. 1990, Sundby \& Fossum 1990). Under the conditions used in one of our simulations, in which prey density was $51^{-1}$, these biases resulted in an underestimate of contact rates by $155 \%$ at a wind speed of $5 \mathrm{~m}$ $\mathrm{s}^{-1}$. Our simulations also suggest that contact rates could be underestimated by as much as 11 -fold for larvae located at frontal regions such as those on the northwest European continental shelf (prey density = $35 \mathrm{l}^{-1}$; Fig. 5). The magnitude of this bias will covary with wind speed and tidal energy, and with temporal and spatial variation in prey density, which is itself subject to other biases (Owen 1989).

Our simulations involving heterogeneously distributed prey considered patchiness on the vertical dimension at scales of 5 to $10 \mathrm{~m}$. Patchiness can exist in all 3 dimensions and at smaller spatial scales (Jenkins 1988 , Owen 1989) than those which we have considered. We expect that the same general principles that we observe would operate at smaller scales (cm's to m's) closer to those of larval feeding activity. Moreover, patchiness on the scale of centimetres persists at wind speeds up to at least $10 \mathrm{~m} \mathrm{~s}^{-1}$ (Jenkins 1988, Owen 1989), although the number of patches, and the density of individuals in the patch, decrease as wind speeds increase (Owen 1989). Consequently, if larvae encounter such a patch, their contact rates with prey will be higher than if prey were homogeneously distributed.
Our empirical evaluation of small-scale turbulence in the mixed layer reveals it to be ubiquitous, though decreasing nonlinearly with depth, to depths of at least $60 \mathrm{~m}$. This indicates that, in general, the surface layer must be considered a turbulent environment (Lueck \& Reid 1984) when judged from the perspective of a larval fish and its prey. This is precisely the habitat occupied by first-feeding larvae of many species of marine fishes (Heath et al. 1988, Fortier \& Harris 1989, Dauvin \& Dodson 1990, Nielson \& Perry 1990). This suggests that larval fish, and more generally zooplankton (e.g. Costello et al. 1990, Marrasé et al. 1990), should possess behaviours that enable them to capture and ingest prey under conditions of moderate turbulence.

As residents of this environment, larval fish are known to be periodically dispersed downwards, or to actively avoid the surface, during strong winds (Heath et al. 1988). Interactions between illumination, windinduced turbulence (Heath et al. 1988), and prey density (Munk et al. 1989) are largely responsible for the vertical distributions of larval herring, and possibly for other species. For example, very high turbulence levels could allow prey to pass through the larva's visual field without being successfully captured because larval reaction times may be too slow to respond to fast-moving prey (e.g. see Checkley [1982] and Govoni et al. [1986] for factors affecting prey selection by larval fishes). In extremely turbulent environments larval feeding success may, therefore, be lower than in less turbulent environments. It is likely, therefore, that larvae use combinations of light, turbulence and prey density to maximize in situ feeding success in the sea during both calm and storm periods.

In particular, larval vision (Hunter 1981, Wanzenböck \& Schiemer 1989), and its dependence on illumination (Blaxter 1988), will influence the encounter radius, $R$. For example, the gut contents of many species of larvae that have been collected at regular intervals throughout the day and night reveal a diel cycle (Arthur 1976, Kellerman 1990, Young \& Davis 1990), even though turbulence continues, and, in some areas even increases, at night (Moum \& Caldwell 1985 , Shay \& Gregg 1986).

The demonstration of the potential effect of smallscale turbulence on contact rates at tidal fronts (Fig. 5) adds to our understanding of processes which enhance biological production in such areas. Previous explanations of the high production and/or standing stocks commonly observed at fronts have focused mainly on the positive effects of increased amounts of phytoplankton cells, light and nutrient conditions, and circulation processes which entrain organisms towards the front (see review by LeFevre 1986). Much of the enhanced production may be attributable to increased 
encounter rates between secondary consumers and their prey as a result of small-scale turbulence characteristic of such regions. High turbulence levels in these areas reduce the size of the smallest eddies, whose mean length scale is related to the Kolmogorov scale (Lazier \& Mann 1989, Granata \& Dickey 1991). This suggests that a larger size range of organisms, and possibly more trophic levels within the planktonic food web, will benefit from the high levels of turbulence found at tidal fronts.

Given the results of our simulation we would expect that in stratified regions of the sea and in lakes, that the relative contribution of wind energy (Lueck \& Reid 1984), and the dependence of the biota on this energy source, will be more important than tidal energy in influencing trophodynamics among planktonic taxa. Moreover, wind energy inputs are less reliable ecological signals than tidal energy inputs. If larval fish and other zooplankton do require turbulence to offset the potentially negative effects of low food densities commonly reported for marine environments (Mackenzie et al. 1990, see also Huntley \& Boyd 1984, Olson \& Olson 1989), populations which inhabit nontidal regions may experience more variable encounter rates, and hence different selection processes, than populations inhabiting areas associated with more reliable inputs of turbulent kinetic energy (e.g. fronts).

Our analyses, like those of Rothschild \& Osborn (1988), indicate that the positive effects of turbulence are greatest on the slowest swimmers (Fig. 1B), which tend to be the smallest larvae (Miller et al. 1988). Firstfeeding and young fish larvae are therefore most likely to benefit from small-scale turbulence. These larvae may, therefore, have lower foraging-related metabolic costs than in the absence of turbulence (Rothschild \& Osborn 1990, also Wieser et al. 1988, Boisclair \& Leggett 1989). As swimming ability develops, larvae are less dependant on extrinsic, abiotic energy sources (winds, tides) as a means to encounter prey (Rothschild \& Osborn 1988). However, even for these larger larvae, should their physiological condition deteriorate to a point where swimming ability is reduced (Blaxter \& Ehrlich 1974, Frank \& Leggett 1982), kinetic energy inputs, such as those that occur during direct windmixing, at fronts (Bowers \& Simpson 1987), and during upwelling (Csanady 1989) can potentially increase contact rates of larvae with their prey.

This could reduce the likelihood that larvae would starve to death in the sea (e.g. Hovenkamp 1990) as well as the likelihood of finding starving larvae in the sea. However, if slow-swimming larvae are indeed dependent on tide- or wind-generated turbulence for increasing their encounter rates with prey, then temporal and spatial changes in tidal circulation and wind speeds could result in intermittent periods of reduced feeding and growth rates (e.g. Buckley \& Lough 1987, Hovenkamp 1990, see also Rothschild \& Osborn 1988). Such changes could occur if (1) winds slacken, which would reduce turbulent motions that otherwise increase contact rates; (2) winds increase by so much that larvae are mixed into, or actively swim towards, depths where light intensities reduce the ability of larvae to see their prey; or (3) larvae are physically displaced by whatever means from 'geographically stable physical oceanographic systems' (Sinclair 1988, p. 37-38) and subsequently experience conditions where reduced turbulence results in lower prey encounter rates than those prevailing prior to displacement.

Reports of periods of intermittently poor larval growth linked to low prey numbers are relatively rare (e.g. Sinclair 1988, p. 137; Mackenzie et al. 1990). This may reflect difficulties in accurately estimating growth rates and larval prey abundance simultaneously. In any case, periods of reduced growth will protract the larval period (Houde \& Schekter 1981, Chambers \& Leggett 1987) and increase the time that larvae are exposed to relatively high mortality (Folkvord \& Hunter 1986). In addition, the weakened condition of slow-growing larvae may make them more vulnerable to some predators (Bailey \& Houde 1989).

\section{A cautionary note}

Our interest in this paper has been to explore quantitatively the potential influence of small-scale turbulence on encounter rates between fish larvae and their prey. The empirical wind-induced turbulence model developed for this purpose represents a first-order description of the variability in small-scale turbulence in nature. It should be remembered also that turbulence it itself patchily distributed and highly intermittent (Gezentsvey 1985, Lazier \& Mann 1989, Yamazaki \& Lueck 1990), and that all of our reported results represent average values for contact rate. A sensitivity analysis of $\mathrm{Eq}$. (1) showed that the $95 \%$ confidence limits of a wind-induced turbulence estimate deviate by a factor of ca 10 from predicted values of $\varepsilon$. However, contact rates derived using these $95 \%$ confidence limits for $\hat{\varepsilon}$ vary only by a factor of ca 3 (Fig. 6). This range approximates the range of biases in estimates of in situ larval food resources when determined by integrative sampling methods which fail to account for microscale plankton patchiness (Owen 1989).

Moreover, the contact rates we report are based on either wind-or tide-generated turbulence. In frontal regions, these effects could interact in an additive way. In addition, coastal upwelling (Csanady 1989), breaking internal waves, fish schools (Farmer et al. 1987) and other processes (Monin \& Ozmidov 1985, Oakey 1985) 


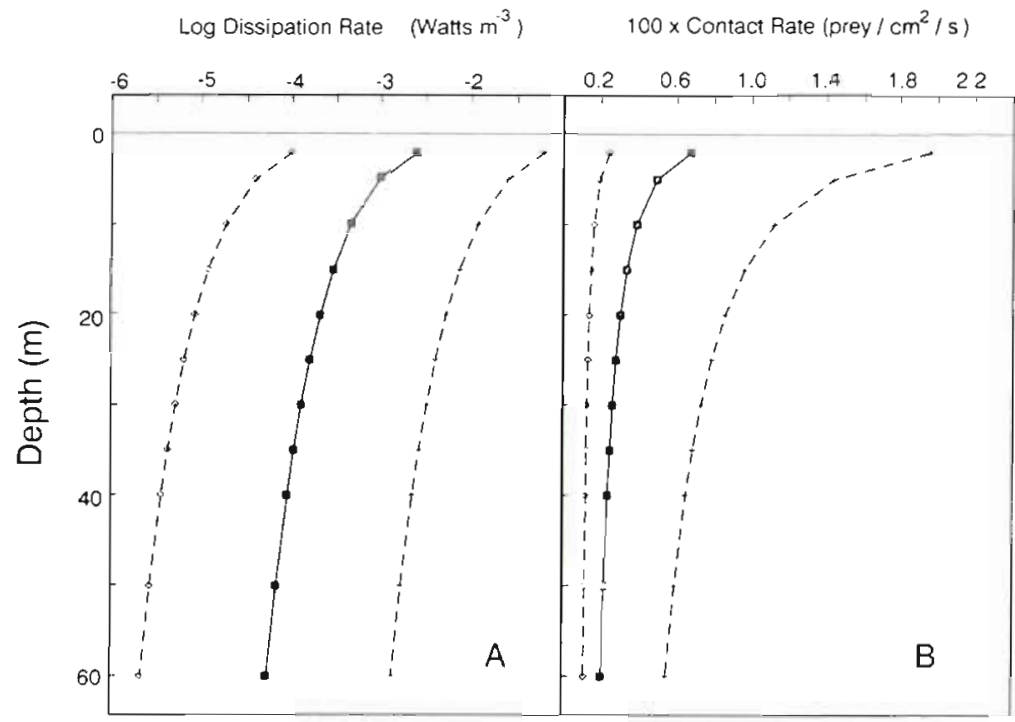

Fig. 6. Sensitivity analysis of the influence of turbulence levels estimated from Eq. (1) on contact rates between larval fish and their zooplankton prey. The wind input used in this analysis is the mean value of $\log \left(W^{3}\right)(2.468 ; W$ $=6.6 \mathrm{~m} \mathrm{~s}^{-1}$ ) in our data set. The indicator variable for the sampling site was given a value of 1 . which represents a coastal habitat. (A) Average dissipation rate of wind-induced turbulent kinetic energy as a function of depth. Dashed lines represent $95 \%$ confidence limits calculated from Eq. (8) in Peters \& Downing (1984). (B) Contact rates for fish larvae and zooplankton prey for the turbulence levels shown in (A) Larval swimming speed is $0.20 \mathrm{~cm} \mathrm{~s}^{-1}$ and prey swimming speed is $0.02 \mathrm{~cm} \mathrm{~s}^{-1}$ Prey density is $51^{-1}$ Note that the $95 \%$ confidence limits for turbulent dissipation rate vary by a factor $>10$ but that the conficence limits of contact rates derived using these confidence limits vary by a factor of ca 3

can produce turbulence in nature which may, in local areas, also influence encounter rates.

It is important, therefore, that more precise models be developed with which to predict the dissipation rate of turbulent kinetic energy, given the apparent importance of small-scale turbulence to plankton ecology. For example, coincident reporting of water column stratification and vertical turbulence profiles, together with wind field records over the sampling interval, could significantly reduce the residual variance associated with Eq. (1) (Lueck et al. 1983, Oakey 1985, Rothschild \& Osborn 1990, Yamazaki 1990). It should be noted, too, that turbulence measurements in the upper mixed layer, including those used in developing Eq. (1), sometimes depart from a lognormal distribution (Yamazaki \& Lueck 1990, Yamazaki et al. 1990). This factor should be considered in the development of future models.

Our results do, however, clearly illustrate the importance of turbulent energy to feeding rates in the plankton, and provide quantified estimates of the relative differences in contact rate that turbulent energy inputs can create in nature. They also provide insights into where in the vertical (wind) and horizontal (tidal) dimensions such increases are most likely to occur. Finally they clearly highlight some of the consequences of fluctuating turbulence levels on the rates of contact between fish larvae and their prey, and indeed, between zooplankton generally and their prey, and of the failure to incorporate knowledge of these effects into analyses of plankton dynamics. These results, and the models from which they are derived, can also aid in the interpretation of in situ larval growth and feeding rates when estimates of prey abundance and turbulance, or at least measures of the wind or tidal velocity which generate this turbulence, are available.
Acknowledgements. B. R.M. was supported by a Postgraduate Scholarship from the Natural Sciences and Engineering Research Council of Canada, and the Groupe Interuniversitaire de Recherches Oceanographiques du Québec. Project funding was provided by grants to W.C.L. from the Natural Sciences and Engineering Research Council of Canada and Fonds pour la Formation de Chercheurs et l'Aide à la Recherche (FCAR, Québec). We thank Dr G. Ingram for advice regarding tidally generated turbulence, and Drs C. Chambers and I Miller for reviewing an earlier draft of the manuscript.

\section{LITERATURE CITED}

Arthur, D. K. (1976). Food and feeding and Iarvae of three fishes occurring in the California current, Sardinops sagax, Engraulis mordax, and Trachurus symmetricus. Fish. Bull. U.S. 74: $517-530$

Bailey, K. M., Houde, E. D. (1989). Predation on eggs and larvae of marine fishes and the recruitment problem. Adv. mar. Biol. 25: 1-83

Blaxter, J. H. S. (1988). Pattern and variety in development. In: Hoar, W. S., Randall, D. J. (eds.) Fish physiology, Vol. XI. The physiology of developing fish Part A: Eggs and larvae. Academic Press, New York, p. 1-58

Blaxter, J. H. S., Ehrlich, K. F. (1974). Changes in behaviour during starvation of herring and plaice larvae. In: Blaxter. J. H. S. (ed.) The early life history of fish. Springer-Verlag, Berlin, p. 575-588

Blaxter, J. H. S., Staines, M. E. (1971). Food searching potential in marine fish larvae. In: Crisp, D. J. (ed.) Proc. 4 th Europ. Mar. Biol. Symp. Cambridge University Press, London, p. $467-485$

Boisclair, D., Leggett, W. C. (1989). The importance of activity in bioenergetics models applied to actively foraging fishes. Can. J. Fish. Aquat. Sci. 46: 1859-1867

Bowers, D. G. Simpson, J. H. (1987). Mean position of tidal fronts in European-shelf seás. Cont. Shelf Res. $7 \cdot 35-44$

Buckley, L. J., Lough, R. G. (1987). Recent growth, biochemical composition, and prey field of larval haddock (Melanogrammus aeglefinus) and Atlantic cod (Gadus morhua) on Georges Bank. Can. J. Fish. Aquat. Sci. 44: 14-25 
Chambers, R. C., Leggett, W. C. (1987). Size and age at metamorphosis in marine fishes: an analysis of laboratoryreared winter flounder ( $P$ seudopleuronectes americanus) with a review of variation in other species. Can. J. Fish. Aquat. Sci. 44: 1936-1947

Checkley, D. M., Jr (1982). Selective feeding by Atlantic herring (Clupea harengus) by larvae on zooplankton in natural assemblages. Mar. Ecol. Prog. Ser 9: 245-253

Checkley, D. M., Jr, Raman, S., Maillet, G. L., Mason, K. M. (1988). Winter storm effects on the spawning and larval drift of a pelagic fish. Nature. Lond. 335: 346-348

Costello, J. H., Strickler, J. R., Marrasé, C., Trager, G., Zeller, R., Freise, A. Y (1990). Grazing in a turbulent environment: behavioral response of a calanoid copepod, Centropages hamatus. Proc. natl Acad. Sci. U.S.A. 87 $1648-1562$

Csanady, G. T. (1989). Energy dissipation and upwelling in a western boundary current. J. phys. Oceanogr. 19; 462-473

Dagg, M. J., Clarke, M. E., Nishiyama, T., Smith, S. L. (1984). Production and standing stock of copepod nauplii, food items for larvae of the walleye pollock Theragra chalcogramma in the southeastern Bering Sea. Mar. Ecol. Prog Ser. 19: 7-16

Dauvin, J.-C., Dodson, J. J. (1990). Relationship between feeding incidence and vertical and longitudinal distribution of rainbow smelt larvae (Osmerus mordax) in a turbid well-mixed estuary. Mar. Ecol. Prog. Ser, 60: 1-12

Dillon, T M., Richmann, J. G., Hansen, C. G., Pearson, M. D (1981). Near-surface turbulence measurements in a lake. Nature, Lond. 290: 390-392

Ellertsen, B., Fossum, P., Solemdal, P., Sundby, S., Tilseth, S. (1984). A case study on the distribution of cod larvae and availability of prey organisms in relation to physical processes in Lofoten. In: Dahl, E., Danielsser, D. S., Møksness, E., Solemdal, P. (eds.) The propagation of cod Gadus morhua L. Arendal, Norway. Flodevigen rapportser 1: $453-477$

Farmer, D. D., Crawford, G. B., Osborn, T. R. (1987). Temperature and velocity microstructure caused by swimming fish. Limnol. Oceanogr. 32: 978-983

Folkvord, A., Hunter, J. R. (1986). Size-specific vulnerability of northern anchovy, Engraulis mordax, larvae to predation by fishes. Fish. Bull. U.S. 84: 859-869

Fortier, L., Harris, R. P., (1989). Optimal foraging and densitydependent competition in marine fish larvae. Mar Ecol. Prog. Ser. 51. 19-33

Frank, K. T., Carscadden, J. E. (1989). Factors affecting recruitment variability of capelin (Mallotus villosus) in the Northwest Atlantic. J. Conseil 45: 146-164

Frank, K. T., Leggett, W. C. (1982). Environmental regulation of growth rate, efficiency, and swimming performance in larval capelin (Mallotus villosus), and its application to the match/mismatch hypothesis. Can. J. Fish. Aquat. Sci. 39 691-699

Gerritzen, J., Strickler, J. R. (1977). Encounter probabilities and community structure in zooplankton: a mathematical model. J. Fish. Res. Bd Can. 34: 73-82

Gezentsvey, A. N. (1985). Vertical turbulence structure and turbulent exchange in the equatorial Pacific Ocean Oceanology 25: 319-323

Govoni, J. J., Ortner, P. B., Al-Yamani, F., Hill, L. C. (1986) Selective feeding of spot, Leiostomus xanthurus, and Atlantic croaker, Micropogonias undulatus, larvae in the northern Gulf of Mexico. Mar. Ecol. Prog. Ser. 28: 175-183

Granata, T. C., Dickey, T D. (1991). The fluid mechanics of copepod feeding in a turbulent flow: a theoretical approach. Prog. Oceanogr 26: 243-261
Haury, L. R., Yamazaki, H., Itsweire, E. C. (1990). Effects of turbulent shear flow on zooplankton distribution. Deep Sea Res. 37: 447-461

Heath, M. R., Henderson, E. W., Baird, D. L. (1988). Vertical distribution of herring larvae in relation to physical mixing and illumination. Mar. Ecol. Prog. Ser. 47: 211-228

Heath, M. R., Leaver, M., Matthews, A., Nicol, N. (1989), Dispersion and feeding of larval herring (Clupea harengus L.) in the Moray Firth during September 1985. Estuar coast. Shelf Sci. 28: $549-566$

Houde, E. D., Schekter, R. C. (1981). Growth rates, rations, and cohort consumption of marine fish larvae in relation to prey concentrations. Rapp. P.-v. Réun. Cons. int. Explor Mer 178: 441-453

Hovenkamp, F. (1990). Growth differences in larval plaice (Pleuronectes platessa) in the Southern Bight of the North Sea as indicated by otolith increments and RNA/DNA ratios. Mar. Ecol. Prog. Ser. 58: 205-215

Hunter, J. R. (1972). Swimming and feeding behaviour of larval anchovy Engraulis mordax. Fish. Bull U.S. 70: 821-838

Hunter, J. R. (1981). Feeding ecology and predation of marine larvae. In Lasker, R. (ed.) Marine fish larvae: morphology, ecology and relation to fisheries. University of Washington Press, Seattle, p. 34-77

Hunter, J. R., Thomas, G. L. (1974). Effect of prey distribution and density on the searching and feeding behaviour of larval anchovy Engraulis mordax. In: Blaxter, J. H. S. (ed.) The early life history of fish. Springer-Verlag, Berlin, p. 559-574

Huntley, M., Boyd, C. (1984). Food-limited growth of marine zooplankton. Am. Nat. 124: 455-478

Jenkins, G. P. (1988). Mikro- and fine-scale distribution of microplankton in the feeding environment of larval flounder. Mar. Ecol Prog. Ser. 43: 233--244

Kellerman, A. (1990). Food and feeding dynamics of the larval Antarctic fish Nototheniops larseni. Mar. Biol. 106: 159-167

Kiørboe, T., Johansen, K. (1986). Studies of a larval herring (Clupea harengus L.) patch in the Buchan area). IV Zooplankton distribution and productivity in relation to hydrographic features. Dana 6: 37-51

Lasker, R. (1975). Field criteria for the survival of anchovy larvae: the relation between inshore chlorophyll maximum layers and successful first feeding. Fish. Bull. U.S. 73: $453-462$

Lazier, J. R. N., Mann, K. H. (1989). Turbulence and the diffusive layers around small organisms. Deep Sea Res. 36: 1721-1733

Lazzaro, X. (1987). A review of planktivorous fishes: their evolution, feeding behaviours, selectivities, and impacts. Hydrobiologia 146: 97-167

LeFèvre, J. (1986). Aspects of the biology of frontal systems. Adv. mar. Biol. 23: 163-299

Lewis, M. R., Horne, E. P. W., Cullen, J. J., Oakey, N. S., Platt, T. (1984). Turbulent motion may control photosynthesis in the upper ocean. Nature, Lond 311:49-50

Loder, J. W., Greenberg, D. A. (1986). Predicted positions of tidal fronts in the Gulf of Maine region. Cont. Shelf Res. 6: $397-414$

Lueck, R., Reid, R. (1984). On the production and dissipation of mechanical energy in the ocean. J. geophys. Res. 89C: 3439-3445

Lueck, R. G., Crawford, W. R., Osborn, T. R. (1983). Turbulent dissipation over the continental slope off Vancouver Island. J. phys. Oceanogr. 13: 1809-1818

MacKenzie, B. R., Leggett, W. C., Peters, R. H. (1990). Estimating larval fish ingestion rates: can laboratory derived values be reliably extrapolated to the wild? Mar. Ecol. Prog. Ser. 67: 209-225 
Marrasé, C., Costello, J. H., Granata, T C., Strickler, J. R (1990). Grazing in a turbulent environment: energy dissipation, encounter rates and the efficacy of leeding currents in Centropages hamatus. Proc. natl Acad. Sci. U.S.A. 87 : $1653-1657$

McLaren, I. A. (1963). Effects of temperature on growth of zooplankton and the adaptive value of vertical migration. J. Fish. Res. Bd Can. 20:685-727

Miller, T. J., Crowder, L. B., Rice, J. A., Marschall, E. A. (1988). Larval size and recruitment mechanisms in fishes: toward a conceptual framework. Can. J. Fish. Aquat. Sci. 45: $1657-1670$

Monin, A. S., Ozmidov, R. V. (1985). Turbulence in the ocean. D. Reidel Publ. Co., Dordrecht

Moum, J. N., Caldwell, D. R. (1985). Local influences on shearflow turbulence in the equatorial ocean. Science 320 : 315-316

Munk, P., Kiørboe, T. (1985). Feeding behaviour and swimming activity of larval herring (Clupea harengus) in relation to density of copepod naupli.. Mar. Ecol. Prog. Ser. 24: 15-21

Munk, P., Kiorboe, T., Christensen, V (1989). Vertical migrations of herring (Clupea harengus) larvae in relation to light and prey distributions. Enrivon. Biol. Fish. 26: 87-96

Murphy. G. I. (1961). Oceanography and variations in the Pacific sardine population. Calif. Coop. Oceanic Fish. Invest. Rep. 8: 55-64

Nielson, J. D., Perry, R. I. (1990). Diel vertical migrations of marine fishes: an obligate or facultative process. Adv. mar Biol. 26: 115-168

Nixon, S. W (1988). Physical energy inputs and the comparative ecology of lake and marine ecosystems. Limnol. Oceanogr. 33: 1005-1025

Oakey, N. S. (1985). Statistics of mixing parameters in the upper ocean during JASIN Phase 2. J. phys. Oceanogr. 15 $1662-1675$

Oakey, N. S., Elliott, J. A. (1982). Dissipation within the surface mixed layer. J. phys. Oceanogr 12: 171-185

Olson, R. R., Olson, M. H. (1989). Food limitation of planktotrophic marine invertebrate larvae: does it control recruitment success? A. Rev. Ecol. Syst. 20: 225--247

Osborn, T R. (1978). Measurements of energy dissipation adjacent to an island. J. geophys. Res. 83C: 2939-2957

Otto, L. Zimmerman, J. T F., Furnes, G. K., Mork, M., Saetre, R., Becker, G. (1990). Review of the physical oceanography of the North Sea. Neth. J. Sea Res. 26: 161-238

Owen, R. W (1989). Microscale and finescale variations of small plankton in coastal and pelagic environments. $J$. mar Res. 47. 197-240

Peterman, M. R., Bradford, M. J. (1987). Wind speed and mortality rate of a marine fish, the northern anchovy (Engraulis mordax). Science 235: 354-356

Peters, R. H., Downing. J. A. (1984). Empirical analysis of zooplankton filtering and feeding rates. Limnol. Oceanogr 29: 763-784

Peterson, W. T., Ausubel, S. J. (1984). Diets and selective feeding by larvae of Atlantic mackerel Scomber scombrus on zooplankton. Mar. Ecol. Prog. Ser. 17. 65-75

Rosenthal, H., Hempel, G. (1970). Experimental studies in feeding and food requirements of herring larvae (Clupea harengus). In: Steele, J. H. (ed.) Marne food chains. Oliver \& Boyd, Edinburgh, p. 344-376

Rothschild, B. J., Osborn, T R. (1988). Small-scale turbulence and plankton contact rates. J. Plankton Res 10: 465-474

This article was submitted to the editor
Rothschild, B. J., Osborn, T R. (1990). Biodynamics of the sea: preliminary observations on high dimensionality and the effect of physics on predator-prey interrelationships. In: Sherman, K., Alexander, L. M., Gold, B. D (eds.) Marine ecosystems: patterns, processes and yields. AAAS, Washington, D.C., p. 71-81

Shay, T J., Gregg, M. C. (1985). Convectively driven turbulent mixing in the upper ocean. J. phys. Ocean. 16: $1777-1798$

Simpson, J. H., Hunter, J. R. (1974). Fronts in the Irish Sea. Nature, Lond. 250: 404-406

Simpson, J. H., Allen, C. M., Morris, N. C. G. (1978). Fronts on the continental shelf. J. geophys. Res. 83C: 4607-4614

Sinclair, M. (1988). Marine populations: an essay on population regulation and speciation. Washington Sea Grant Program, University of Washington Press, Seattle

Sundby, S., Fossum, P. (1990). Feeding conditions of ArctoNorwegian cod larvae compared with the RothschildOsborn theory on small-scale turbulence and plankton contact rates. J. Plankton Res. 12: 1153-1162

Taggart, C. T., Leggett, W C. (1987). Short-term mortality in post-emergent larval capelin Mallotus villosus. II. Importance of food and predator density, and density-independence. Mar. Ecol. Prog. Ser. 41 219-229

Tennekes, H. Lumley, J. L. (1972). A first course in turbulence. MIT Press, Cambridge, Massachusetts

Thorpe, S. A. (1985). Small-scale processes in the upper ocean boundary layer. Nature, Lond. 318: 519-522

Veth, C. (1990), Turbulence measurements in the tidallymixed southern bight of the North Sea. Neth. J. Sea Res. 25: $301-330$

Wanzenböck, J., Schiemer, F. (1989). Prey detection in cyprinids during early development. Can. J. Fish. Aquat. Sci 46: 995-1001

Wieser, W., Forstner, H., Medgyesy, N., Hinterleitner, S. (1988). To switch or not to switch: partitioning of energy between growth and activity in larval cyprinids (Cyprinidae: Teleostei). Funct. Ecol. 2: 499-507

Williams, R., Conway, D. V P., Collins, N. R. (1987). Vertıcal distributions of eggs, nauplii and copepodites of Calanus helgolandicus (Copepoda; Crustacea) in the Celtic Sea. Mar. Biol. 96: 247-252

Yamazaki, H. (1990). Stratified turbulence near a critical dissipation rate. J. phys. Oceanogr. 20: 1583-1598

Yamazakı, H., Kamykowski, D. (1991). The vertical trajectories of motile phytoplankton in a wind-mixed water column. Deep Sea Res. 38: 219-241

Yamazakı, H., Lueck, R. (1990). Why oceanic dissipation rates are not lognormal. J. phys. Oceanogr 20: 1907-1918

Yamazaki, H., Lueck, R. G., Osborn, T (1990). A comparison of turbulence data from a submarine and a vertical profiler. J. phys. Oceanogr 20:1778-1786

Yamazaki, H., Osborn, T. R. (1988). Review of oceanic turbulence: implications for biodynamics. In: Rothschild, B. J. (ed.) Toward a theory on biological-physical interactions in the world ocean. NATO ASI Series (Series C: Mathemat1cal and Physical Sciences Vol. 239!. Kluwer Academic Publishers, Dordrecht, p. 215-234

Young, J. W. Davis, T L. O. (1990). Feeding ecology of larvae of southern bluefın, albacore, and skipjack tunas (Pisces: Scombridae) in the eastern Indian Ocean. Mar. Ecol. Prog. Ser. $61 \cdot 17-30$

Manuscript first received: November 8, 1990

Revised version accepted: April 11, 1991 